\title{
O trabalho docente nos Institutos Federais no contexto de expansão da educação superior
}

\author{
Paula Francisca da Silva ${ }^{1}$ \\ Savana Diniz Gomes Melo²
}

\section{Resumo}

Este artigo apresenta e discute alguns dos resultados de uma pesquisa concluída em 2015, que analisou o processo de reordenamento da Rede Federal de Educação Profissional e Tecnológica no contexto da expansão da educação superior, bem como sua repercussão sobre o trabalho dos docentes dos cursos superiores dos Institutos Federais. Por meio desta pesquisa, buscou-se identificar o que interferia no exercício da docência nos cursos superiores, a fim de compreender quais condições, facilidades, problemas ou dificuldades são encontrados pelos docentes em sua atuação. A investigação teve caráter qualitativo e utilizou, como instrumentos de coleta de dados, a pesquisa documental, a observação e entrevistas. 0 estudo evidenciou que a oferta de educação superior em meio às reformas da educação profissional e tecnológica vem se consolidando na Rede Federal de Educação Profissional e Tecnológica desde 2008, por meio dos Institutos Federais, que atuam como agentes de expansão da educação superior. A experiência estudada foi o processo de reordenamento, também chamado de ifetização, do Instituto Federal do Norte de Minas Gerais (IFNMG), com foco nas condições de trabalho dos docentes que atuam nas graduações. A forma como a expansão da instituição e de seus cursos ocorre submete os docentes a condições de trabalho precárias, já que não lhes são possibilitadas todas as condições materiais necessárias. Não obstante, espera-se dos docentes um perfil multifuncional, com vistas a desenvolver múltiplas atividades e cobrir as lacunas institucionais. 0 estudo revelou peculiaridades nas condições de trabalho docente nos cursos superiores da instituição e também demonstrou a existência de generalidades que se apresentam para o conjunto desses trabalhadores na atualidade.

\section{Palavras-chave}

Expansão da educação superior - Institutos Federais - Trabalho docente.

1- Instituto Federal do Norte de Minas Gerais (IFNMG). Montes Claros, MG, Brasil, e Universidade Federal de Minas Gerais (UFMG). Belo Horizonte, MG, Brasil. Contato: paulafransilva@yahoo.com.br.

2- Universidade Federal de Minas Gerais (UFMG). Belo Horizonte, MG, Brasil. Contato: sdgmufmg@gmail.com.

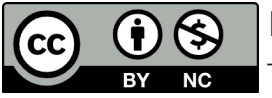




\section{Faculty work on Federal Institutes in the context of higher education expansion ${ }^{3}$}

\section{Abstract}

The present paper presents and discusses some of the results of a research conducted in 2015, which analyzed the process of rearrangement of the Federal Professional and Technical Education Network in the context of the expansion of higher education, as well as its impact on the work of Federal Institute faculty members. It sought to identify what interfered with higher-education teaching, in order to understand the conditions, advantages, problems and hindrances found by teachers in their professional exercise. Research was qualitative in nature, and used documentary research, observation and interviews as data collection tools. The study evidenced that higher-education offer in the midst of professional and technical education reform had been consolidating in the Federal Professional and Technical Education Network since 2008, by means of Federal Institutes, which have acted as higher-education expansion agents. The experience under study was the rearrangement process, also called ifetization, of the Instituto Federal do Norte de Minas Gerais [Federal Institute of Northern Minas Gerais] (IFNMG), with an emphasis on the work of faculty members in undergraduate programs. As it happened, expansion placed teachers under insufficient work conditions, as it failed to provide them the necessary means. However, faculty members were expected to have a multifunctional profile, with a view to develop multiple tasks and fill institutional gaps. Research revealed the peculiarities in teaching work conditions in the institution's higher education programs, and also demonstrated the existence of more general conditions currently in place for these workers.

\section{Keywords}

Higher education expansion - Federal Institutes - Teaching.

\section{Introdução}

Este artigo apresenta e discute os principais resultados de uma pesquisa concluída em 2015 (SILVA, 2015) ${ }^{4}$, cujo objetivo foi analisar o processo de reordenamento da Rede Federal de Educação Profissional e Tecnológica (REFT), no contexto da expansão da

3- Translation by Fabiano Seixas Fernandes. E-mail: fabiano.seixas.fernandes@tradizer.com.

4- Dissertação de mestrado desenvolvida na linha de pesquisa Políticas Públicas em Educação, da Faculdade de Educação da Universidade Federal de Minas Gerais (FaE/UFMG). 
educação superior e sua repercussão sobre o trabalho dos docentes dos cursos superiores dos Institutos Federais (IF).

Convém esclarecer que as condições de trabalho dos docentes dos IF foram compreendidas como o conjunto de recursos que possibilitam a realização do trabalho, envolvendo as instalações físicas, os materiais e insumos disponíveis, os equipamentos e meios de realização das atividades e outros tipos de apoio necessários, dependendo da natureza da produção, ou seja, condições de emprego e condições objetivas de trabalho (OLIVEIRA; ASSUNÇÃO, 2010). Já a oferta de educação superior nos IF foi estudada como uma ação da política pública de expansão da educação superior que acarreta mudanças na estrutura, na finalidade, na organização, na gestão, no perfil do público-alvo e no trabalho dos seus servidores.

Tal política é entendida como uma escolha do governo para com a educação formal que não se desvincula do contexto político, econômico e social em que está inserida. Assim, o processo de expansão da educação superior e sua particularidade nos IF são compreendidos como multifacetados e dialéticos, considerando duas dimensões para análise: as transformações que aconteceram na sociedade em âmbito mundial e desencadearam as reformas na economia, na política e na educação no Brasil após a década de 1990, e a instituição pesquisada, o Instituto Federal do Norte de Minas Gerais (IFNMG), no contexto de reordenamento da rede a que se vincula.

Com relação à primeira dimensão, destaca-se a reforma do Estado brasileiro, iniciada na década de 1990, que, sob orientação de organismos internacionais, apresentou diretrizes e vem promovendo mudanças para acomodar e ajustar o capitalismo à sua nova fase de expansão. Essas mudanças promoveram alterações no papel social da escola, em cujo bojo se situam as transformações em curso na educação superior e na educação profissional e tecnológica (EPT).

Um elemento que caracteriza o conjunto de ações adotadas desde então são as políticas sociais focalizadas, que surgem para conter demandas dos segmentos mais pobres e, ao mesmo tempo, substituir políticas de caráter universal, reduzindo, assim, o caráter da política pública, de dimensão universal, ainda que formal, para a pública focalizada.

Na dimensão micro da pesquisa, o IFNMG se constitui como campo de estudo e revelou peculiaridades, bem como generalidades do trabalho docente no atual contexto de expansão da educação superior no Brasil. A investigação, de caráter qualitativo, buscou identificar o que interferia no exercício da docência nos cursos superiores do IFNMG e, para tanto, utilizou como instrumentos de coleta de dados a pesquisa documental, a observação e entrevistas; como tratamento analítico, utilizou a análise de discurso.

Em um esforço de síntese da pesquisa, este texto apresenta alguns de seus resultados e dados em três partes. A primeira aborda o processo de expansão da educação superior a partir da década de 1990. A segunda discute a oferta de educação superior e o trabalho docente nos Institutos Federais. A terceira parte analisa o processo de constituição do IFNMG e as condições de trabalho dos docentes que protagonizam e vivenciam o processo de expansão dos cursos superiores na instituição. 


\section{A expansão da educação superior a partir da década de 1990}

A expansão da educação superior no Brasil é recente e vivencia a sua segunda onda de crescimento. A primeira pôde ser observada até a década de 1980 e a segunda, a partir do final da década de 1990 (NEVES, 2012). Em ambos os períodos, a expansão ocorreu, predominantemente, pela via privada, mas, a partir de 2003, ganhou características peculiares.

Antes de tratar dessas peculiaridades, é interessante perceber a atual fase de expansão da educação superior como fruto do processo de reestruturação capitalista (BERNARDO, 2004), iniciado no final da década de 1970.

A instabilidade é algo inerente ao capitalismo e, na procura por equilíbrio, esse sistema passa por constantes processos de ajustamento, acomodação, reorganização e reestruturação das suas formas de produção e organização social, em busca de sua reprodução e perpetuação. Em meio a tantas estratégias, a formação e a inserção da força de trabalho nos processos produtivos apresentam-se como requerimentos vitais. Essa característica reforçou a ideia de educação, em especial a superior, como um requisito indispensável ao desenvolvimento econômico e social de um país (MAUÉS, 2010). Com tal entendimento, as reformas do Estado e da legislação educacional brasileira têm colaborado, veementemente, para consubstanciar esse propósito. Nesse contexto, foram empreendidas, paulatinamente, reformas dirigidas à educação superior, à educação básica e à EPT, entre outras, aparentemente desconectadas, mas profundamente concatenadas ao novo modelo de educação que se busca criar no país, orientado pela lógica do mercado.

Destacam-se, nessas reformas em nível superior, a ampliação, a expansão e a flexibilização das ofertas e oportunidades de formação. Como resultados desse processo, proliferaram-se no Brasil modelos de instituições cada vez mais diversificados e cursos mais flexíveis, na busca por redução de gastos públicos, abertura comercial e privatizações por meio de legislações educacionais, entre outras medidas que reconfiguram o campo da educação superior brasileira (SILVA JR.; SGUISSARDI, 2001).

Um comparativo entre os dados do Censo Nacional da Educação Superior (CENSUP) de 1995, 2003 e 2013 permite mensurar a magnitude e os contornos alcançados por essas ações. 0 número total de instituições de ensino superior (IES) no Brasil aumentou consideravelmente, de 1995 a 2013: em 1995, existiam 894 IES; em 2013, foram registradas 2.391. A maior variação, nesse período, pôde ser observada entre 1995 e 2003, período em que o crescimento total do número de IES representou 108\%. Tal aumento só foi possível em virtude do crescimento acelerado de IES particulares: foram criadas mais 968 IES particulares, o que significou um aumento percentual de $142 \%$. Já o número de IES públicas diminuiu: em 1995, existiam 210 IES e, em 2003, o CENSUP registrou 207.

No período subsequente, de 2003 a 2013, apesar de o número de IES particulares continuar crescendo, o número de IES públicas aumentou. Foram criadas 94 novas IES públicas, e isso representou um aumento percentual de 45\% no número total de IES no Brasil. Em suma, após 2003, a educação superior pública registrou um crescimento significativo, embora menor que no setor privado. 
Acompanhando o crescimento de IES, a oferta de vagas também aumentou no período observado. Houve um aumento considerável no número de matrículas na educação superior, que passou de 1.759.703, em 1995, para 3.887.022, em 2003, ou seja, o quantitativo mais que dobrou. De 2003 a 2013, o número de matrículas quase duplicou novamente, subindo para 7.305.977.

As IES privadas detêm o maior número de matrículas. A expansão da educação superior via rede privada foi privilegiada, em detrimento da expansão via rede pública. No entanto, verifica-se um crescimento significativo no número de matrículas na educação superior pública, principalmente após o ano de 2003. 0 número de matrículas nas instituições federais de ensino (IFES), no período de 2003 a 2013, foi 83\% maior do que o registrado no período de 1995 a 2003. A literatura constata que houve restrições à expansão da educação superior pela via pública no período de 1995 a 2002 (AMARAL, 2008; GOMES; MOARES, 2012). Após iniciativas adotadas pelo Governo do Presidente Luiz Inácio Lula da Silva (2003-2010), com continuidade no Governo da Presidente Dilma Rousseff (2011-2016), o cenário foi revestido de singularidades.

Para atingir os patamares aspirados de desenvolvimento nacional, recomendados pelos organismos internacionais, foram desencadeadas ações de reordenamento das IES públicas, com princípios de otimização de espaços e tempos, de ampliação e criação de oferta, de redução ou flexibilização de recursos materiais e humanos. Com isso, ganharam destaque, na política educacional brasileira, medidas de incentivo ao crescimento da educação superior pública. É possível elencar, nesse campo, o Programa de Apoio a Planos de Reestruturação e Expansão das Universidades Federais (REUNI), ${ }^{5}$ a flexibilidade posta pela regulamentação da educação a distância (EaD), bem como a criação do Sistema Universidade Aberta do Brasil (UAB); ${ }^{6}$ a instituição do Sistema de Seleção Unificada (SISU); a reestruturação da REFT e a criação dos IF, apresentados como um novo modelo de IES a partir de 2008. Por outro lado, as estratégias de favorecimento da educação superior privada continuaram, mas com uma peculiaridade: o alto investimento de dinheiro público nas IES particulares. Tais investimentos foram favorecidos, a partir de 2004, por programas como o Programa Universidade para Todos (PROUNI) e o Fundo de Financiamento do Ensino Superior (FIES), que, a partir de então, passam a ser utilizados como estratégias para alcançar as metas do Plano Nacional de Educação (PNE): reduzir as pressões dos até então excluídos da educação superior e, ao mesmo tempo, fortalecer o mercado educacional.

Todas essas ações repercutiram fortemente sobre o trabalho docente, acarretando-lhe novas atribuições e demandas, sem, contudo, oferecer as devidas condições de trabalho. Tal fato provoca uma nova onda de intensificação e precarização do trabalho dos professores e diretores escolares.

Os professores passaram a ser tensionados por várias modalidades de avaliação, que contribuíram para sua responsabilização e culpabilização; para a introdução de formas de retribuição financeira, associadas ao cumprimento de metas de desempenho

\footnotetext{
5- Instituído pelo Decreto n 6.096/2007, previu uma expansão que intencionava dobrar o número de matrículas até 2012.

6- Decreto $n^{\circ} 5.622 / 2005$ e Decreto $n^{0} 5.800 / 2006$.
} 
dos estudantes; e para a conformação de um ranking das escolas, mecanismo fundamental para o funcionamento do mercado que se aspira conformar.

\section{A oferta de educação superior e o trabalho docente nos Institutos Federais}

Entre reformas da EPT e interveniências dos organismos internacionais, os Centros Federais de Educação Tecnológica (CEFET) iniciam um modelo de educação superior alternativo, que se firmou com os novos CEFET, passou pelas Escolas Agrotécnicas Federais (EAF), tornou-se proeminente na Universidade Tecnológica do Paraná (UTFPR) e, mais tarde, consolidou-se nos IF. Segundo Lima Filho (2002), esse modelo é diferente do universitário, pois é dirigido ao ingresso imediato no mercado de trabalho, em lugar do envolvimento com pesquisas, estudos acadêmicos, científicos, éticos e políticos. Tal modelo passou a ocupar lugar de notoriedade nas políticas educacionais brasileiras após 2003 e se configura como uma educação vinculada às necessidades e demandas dos arranjos produtivos locais (APL), o que tem início já na educação básica, por meio dos cursos técnicos integrados ao ensino médio.

Nesse cenário, a Lei n ${ }^{\circ} 11.892 / 2008$ reestrutura a REFT e cria os IF, a partir da reorganização dos antigos CEFET, EAF e Escolas Técnicas, que, após sofrerem sucessivas alterações impostas por medidas legais, angariam status de IES, com funções para além das de uma universidade: são ofertantes de cursos superiores em nível de graduação e pós-graduação, sob o princípio da indissociabilidade entre ensino, pesquisa e extensão, sem deixar de ser instituições de educação básica, comprometidas com a transformação social e o desenvolvimento regional (BRASIL, 2010).

Os IF, em sua nova institucionalidade, são apresentados como detentores de muitas vantagens e com a possibilidade de atender a alguns problemas da sociedade brasileira. Em primeiro lugar, a verticalização do ensino, que orienta a filosofia e as finalidades dos IF, prima pela otimização de infraestrutura, recursos humanos e materiais. Por assim serem, são mais econômicos e flexíveis que as universidades, como bem requerem os organismos internacionais. Em segundo lugar, a oferta de educação superior pode contribuir com a expansão desse nível de ensino e com o alcance das metas do PNE, que, até então, o país tem tido dificuldades em atingir. Em terceiro, destaca-se o desenvolvimento de pesquisa aplicada e da extensão, ligadas a serviços técnicos que favorecem o desenvolvimento regional e os colocam a serviço das questões sociais. Em quarto, o vínculo dessas instituições com os APL pode favorecer o desenvolvimento regional e as relações do governo com os setores produtivos. Em quinto, situa-se a natureza peculiar e múltipla dos IF, que permite abrigar uma gama de projetos e programas de distintas dimensões da tríade (ensino, pesquisa e extensão) e, assim, atender a públicos diferentes. Em sexto, essas instituições podem resolver problemas mais imediatos da sociedade, com a formação de mão de obra rápida de nível fundamental, médio e superior, por meio dos cursos de formação inicial e continuada (FIC), técnicos e superiores de tecnologia. Por último, como asseguram vagas para as licenciaturas, podem auxiliar na formação de professores para a educação básica e EPT. 
A oferta de educação superior nos IF está garantida pela lei de criação dessas instituições, com peculiaridades específicas: 20\% das vagas para cursos de licenciatura e formação pedagógica, e outros 30\% para cursos superiores de tecnologia, bacharelado, engenharias e cursos de pós-graduação.

De acordo com orientações governamentais presentes no documento intitulado Uma nova proposta de Educação Profissional Tecnológica: concepções e diretrizes dos Institutos Federais (BRASIL, 2010), tais peculiaridades têm razões fundamentadas na demanda da sociedade. Com a oferta de licenciaturas, é possível colaborar para: suprir a carência de professores; alcançar a meta de universalização do ensino médio; resolver o problema da predominância da atuação de técnicos e bacharéis nos mais variados campos e, na última década, maciçamente, a presença dos tecnólogos e/ou bacharéis na função docente. Com os cursos superiores de tecnologia, a instituição colabora com uma formação rápida e mais direcionada à produção de conhecimento mais específico. Já com a oferta de cursos de engenharias, contribui com a preparação de mão de obra, que cria e produz bens de grande valor agregado, que pesam na balança comercial do mundo globalizado.

Contrariando as expectativas, os IF têm esbarrado em dificuldades e contradições, ao buscarem auxiliar na solução para tais problemas da sociedade. Exemplo disso é que a exigência dos cursos superiores nos IF não vem acompanhada da exigência de formação pedagógica dos docentes. Por esse motivo, hoje, vários cursos de licenciatura e de capacitação pedagógica contam com docentes não licenciados lecionando em cursos de formação de professores (OTRANT0, 2013).

Nessa instituição complexa e com ampla função social, os docentes da carreira do Magistério da Educação Básica, Técnica e Tecnológica (EBTT) protagonizam uma das vertentes do atual processo de expansão da educação superior. A atuação desses docentes chama a atenção por se efetivar em meio a sucessivos processos de construção e reconstrução, que alteram significativamente os objetivos e as finalidades que a instituição tem a cumprir. Os objetivos abarcam e compreendem vários elementos e/ou aspectos distintos, aliados ao alcance de metas de expansão estipuladas pelo governo, em espaços de tempo, na maioria das vezes, muito curtos. Soma-se a isso a falta de condições materiais e/ou imateriais, que abarca desde o quadro de pessoal, até a infraestrutura dessas instituições. Paralelamente, os docentes têm que corresponder às expectativas da população e dos setores produtivos da região na qual os IF se instauram, igualmente, sem os meios e a compreensão necessária de seu significado.

Tensionamentos distintos revelam a complexidade e a intensificação do trabalho docente também nos IF.

Todas essas atividades exigem do trabalho docente mais flexibilidade e proximidade na relação com os estudantes e com outros contextos e ambientes de trabalho (MELO, 2010). Além disso, é necessária uma relação íntima do profissional, tanto com a esfera da educação básica como da educação superior (MACHAD0, 2008). Desse modo, o trabalho desses docentes é marcado pela complexidade intrínseca à EPT, somada à heterogeneidade da educação superior.

A não preparação do professor do IF para lidar com toda essa complexidade também merece ser destacada. Nem a docência para a educação superior nem para a EPT está 
regulamentada sob a forma de um curso específico, o que reforça a preocupação com o crescente número de profissionais não qualificados nessas áreas.

Outro ponto de tensão do trabalho docente nos IF é a vinculação quase orgânica que a relação dessas instituições com os APL exige dos docentes. Por intermédio de documentos oficiais do Ministério da Educação e da Secretaria de Educação Profissional e Tecnológica (MEC-SETEC) (BRASIL, 2003, 2009, 2010), estabelece-se que todas essas atividades docentes devem ser desenvolvidas em colaboração com os APL, face à estreita articulação dos IF firmada com os setores produtivos, principalmente na proposta de geração e adaptação de soluções técnicas e tecnológicas e na oferta formativa, em benefício dos APL. Para Grischke (2013), esse vínculo com os APL implica uma nova institucionalidade, que repercute uma configuração mais flexível e inovativa em relação à organização do trabalho escolar e docente.

Soma-se a isso a tensão causada por uma série de medidas governamentais que eclodiram em 2015, no bojo do ajuste estrutural. Entre elas, está a minirreforma trabalhista, imposta pelas Leis $\mathrm{n}^{0} 13.134 / 2015$ e 13.135/2015, que flexibilizaram os direitos trabalhistas, ao restringirem o acesso do trabalhador ao seguro-desemprego, ao abono salarial e ao seguro defeso; o aumento da taxa de juros; os cortes de orçamento da União que, na educação superior, entre outras, prejudicaram o desenvolvimento adequado das atividades básicas de ensino, pesquisa e extensão, comprometendo a consolidação e a expansão das IFES no país. Diante de tantos cortes que apontam para a privatização do setor público da educação, como manter as atividades e ainda consolidar essa expansão da educação superior com qualidade? É o que preocupa os trabalhadores da educação e impulsionou uma série de greves ao longo dos últimos anos.

Paralelamente, ocorreu a aprovação do projeto de regulamentação da terceirização de serviços e a aprovação das contratações no setor público, por meio de Organizações Sociais (OS), pelo Supremo Tribunal Federal. Tal fato coloca em risco tanto a garantia dos direitos dos servidores públicos, quanto a oferta pública e gratuita e a qualidade dos serviços prestados.

Outra medida muito polêmica foi a proposta de melhoria do ensino básico, expressa no documento Pátria Educadora: a qualificação do ensino básico como obra de construção nacional (BRASIL, 2015), que representa o avanço da perspectiva empresarial na definição e na implementação de políticas públicas no campo da educação. 0 discurso propalado pelo documento contraria grande parte das reivindicações dos docentes, técnicos e estudantes, e dá continuidade à reforma empresarial da educação, que foi anunciada em 1995 e é regida pela responsabilização, pela meritocracia e pela privatização (FREITAS, 2012).

A docência nos IF possui ainda, como foco de tensão, os processos de avaliação externa. Os IF, tal como as demais IES, exigem uma atuação docente cada vez mais quantitativista. A busca incessante por alcance de metas e números tem quebrado a rotina das IES e colocado os docentes à mercê da burocracia institucional, do produtivismo acadêmico, da pressão psicológica, da intensificação do trabalho e, na maioria das vezes, da frustração, já que o mesmo governo que lhes impõe metas não oferece as condições necessárias para alcançá-las, depois os avalia, responsabiliza e pune. Os resultados dessas avaliações nas IES, em geral, têm sido usados para justificar a diferenciação de 
competência ou, até mesmo, classificar e ranquear dentro de uma mesma instituição, servindo até como referência para distribuição de recursos, como já referido. Esse modelo de avaliação tem sido muito importante para estabelecer e consolidar a lógica mercantil da educação superior, pois, por meio dele, controla-se o desempenho das IES frente ao estabelecimento de padrões; estimulam-se a eficiência, a eficácia e a produtividade nas tarefas das instituições, enquanto instrumento do desenvolvimento econômico; atende-se a interesses utilitaristas e de homogeneização, que requerem padronização nas informações, nas avaliações e na prestação de contas, com foco no cumprimento de metas e objetivos; possibilita-se o estabelecimento de rankings para servir de nivelamento qualitativo, enquanto produto, o que, por conseguinte, estimula a competitividade (SERAFIM, 2011).

Diante de tantos tensionamentos, os primeiros anos de trabalho dos docentes nos IF foram turbulentos, e a expressão desse fenômeno pode ser observada nos conflitos vivenciados na REFT, com diferentes motivações e formas. O Sindicato Nacional dos Servidores Federais da Educação Básica, Profissional e Tecnológica (SINASEFE), por exemplo, protagonizou quatro grandes greves nacionais: em 2011, 2012, 2014 e 2015. A busca por melhores condições de trabalho e por uma educação pública de qualidade foram as principais pautas que movimentaram a luta da categoria.

A aprovação da Lei no 12.772/2012, ao final da greve de 2012, aproximou a carreira do magistério da EBTT da carreira do magistério da educação superior (MS). Destaca-se, nesse plano, a equivalência de valores na composição remuneratória entre as carreiras do MS e EBTT. No entanto, ainda perduram a falta de diálogo e de continuidade das negociações entre a categoria docente e o Governo Federal; o arrocho salarial; as gratificações que são incorporadas parcialmente quando ocorre a aposentadoria; a falta de isonomia estampada na cisão entre as carreiras do MS e EBTT; a ineficiência do plano, no que se refere à entrada e à permanência dos docentes na carreira, bem como na conquista do reconhecimento social do docente EBTT; e as possiveis estratégias de contenção de gastos e busca por formação continuada, que estão por trás de medidas como o Reconhecimento de Saberes e Competências (RSC).

Um resultado auferido nesse contexto foi a precarização do trabalho docente, expressa nas condições de emprego, no que diz respeito ao tempo de trabalho ou regime de trabalho, no âmbito dos IF. Apesar de as IES públicas serem as que mais contratam professores em regime de trabalho integral e parcial, existem contratos em regime horista (substituto e temporário). 0 uso de contratos supostamente mais ágeis e econômicos nessas instituições converge para a adoção de um novo modelo gerencial que reproduz um mercado de trabalho flexível. Ao mesmo tempo, as contratações em regime integral não têm sido garantia de melhores condições para a dedicação à pesquisa e à extensão, no âmbito das IFES. Pelo menos, é isso que pesquisas recentes sobre a expansão da educação superior pública, em especial as que tratam do efeito do REUNI, evidenciam (COSTA; BRAGA; FERREIRA, 2014; PAULA, 2015). Está em curso uma onda de intensificação e precarização do trabalho docente e do ensino, em virtude de um movimento de reconfiguração que acomete as IFES brasileiras.

As políticas de expansão da educação superior implementadas direcionam a uma educação cada vez mais mercantilista, que se caracteriza por: piora nas relações de contrato 
trabalhista; achatamento salarial dos aumentos concedidos apenas nas gratificações; aumento na rotina de atividades de ensino, pesquisa e extensão; ausência de contratação de funcionários técnico-administrativos; individualismo; clima de competitividade entre docentes, marcado pela avaliação quantitativa da lógica do mercado.

\section{A experiência do Instituto Federal do Norte de Minas Gerais (IFNMG)}

A experiência do IFNMG, enquanto instituição em processo de ifetização e, ao mesmo tempo, como agente de expansão da educação superior, foi estudada com o objetivo de conhecer as mudanças postas às instituições em processo de transformação em IF. Além disso, tratou-se da oportunidade de evidenciar as alterações presentes no cotidiano da instituição e em seus documentos oficiais, junto daquelas alterações percebidas e sentidas pelos docentes.

Para tanto, foram utilizados, como instrumentos de coleta de dados, a observação, a pesquisa documental e entrevistas. A observação e a pesquisa documental auxiliaram na caracterização do IFNMG, na compreensão do processo de idealização, implantação e oferta de cursos superiores na instituição, bem como na apreciação da atuação do docente nesses cursos. Já as entrevistas buscaram identificar a percepção dos docentes sobre as mudanças na instituição e no seu trabalho.

Foram entrevistados dez docentes, com perfis variados: gestores da reitoria e dos campi, regentes, pesquisadores, sindicalistas e atuantes na extensão. 0 objetivo foi considerar pontos de vista diferentes sobre o processo de ifetização da instituição. As informações recolhidas foram organizadas em quatro categorias: estrutura, administração/gestão, finalidades e trabalho docente. Tais categorias foram subdivididas em subcategorias, ${ }^{7}$ que apresentam detalhes do processo de transformação da instituição em IF e da repercussão dessa transformação sobre o trabalho docente.

A análise das entrevistas revelou fortes tensões, não só entre os discursos dos sujeitos, mas também no discurso de um mesmo sujeito. Tais tensões se tornaram mais evidentes nas relações de sofrimento e prazer no exercício da docência e de reconhecimento e não reconhecimento de certas situações que estavam vivenciando, no contexto de ifetização e expansão da instituição e de seus cursos superiores.

Foi possivel perceber, ainda, que as falas dos docentes que ocupavam cargos de gestão na instituição estavam mais alinhadas aos discursos institucionais e governamentais; no entanto, reconheciam os desafios postos à instituição, pela intensificação do trabalho docente e pelos concomitantes processos de expansão da instituição e dos seus cursos superiores. Nos relatos dos docentes que não atuavam em cargos de gestão, os problemas

\footnotetext{
7- Foram subcategorias da pesquisa: a) Estrutura: área de abrangência e organização (natureza jurídica e identidade visual); b) Administração/ gestão da instituição: desenho organizacional e financiamento; c) Finalidades: tríade ensino, pesquisa e extensão, que, por sua vez, foi subdividida em Ensino (objetivos do ensino, oferta de cursos, matrículas, tempo e espaço) e Programas e projetos; d) Trabalho docente: atribuições dos docentes nos cursos superiores (atividades de ensino, atividades de pesquisa e extensão e atividades de gestão institucional); e) Condições de trabalho (condições de emprego, condições materiais, quadro de pessoal, tempo de trabalho, formação, relações sociais, avaliação, arranjos produtivos locais e organização política e sindical).
} 
que surgiram na instituição com os processos de expansão, como a falta de recursos materiais e humanos, foram apontados e reconhecidos com mais facilidade, pois são diretamente afetados por eles.

Fato é que todos os docentes, de uma maneira ou de outra, percebem as alterações que aconteceram no IFNMG e encontram dificuldades advindas da rápida expansão que a instituição e seus cursos sofreram nos últimos anos.

Entre as alterações ocorridas no IFNMG, destacam-se aquelas postas por decisões externas e/ou verticalizadas: a natureza jurídica; a autonomia institucional; a forma de organização por agrupamento de escolas; a finalidade e a identidade visual da instituição.

Segundo o texto da Lei $\mathrm{n}^{\circ}$ 11.892/2008, os IF são apresentados como uma grande novidade, mas, na verdade, essas instituições sofreram um processo de reestruturação, pois foram criadas a partir da transformação de antigas instituições já consolidadas que, para tanto, deixaram de ser autarquias. Com o IFNMG, não foi diferente. Em meio ao processo de reordenamento da REFT, nasceu o IFNMG, fruto da união entre o CEFET de Januária (MG) e a EAF de Salinas (MG). Duas autarquias federais independentes deixaram de existir para dar origem a uma única autarquia, após a transformação em IFNMG. Essa união não foi simples, ocorreu sob um clima de tensão, insegurança, expectativas e temores, diante do caráter vertical do novo modelo de IES instituído.

Onze novas escolas se agruparam em torno de uma sede, com um reitor. Os símbolos, os objetivos e as finalidades do IFNMG passaram a ser os mesmos dos IF que compõem a IFNMG. As antigas autarquias - CEFET-Januária e EAF-Salinas - perderam até mesmo suas identidades visuais. As cores institucionais, suas bandeiras e seus brasões foram extintos, dando lugar à adoção de uma identidade única e comum a todos os IF espalhados pelo país. Uma nova configuração que exige dos docentes dinamismo e habilidade para se acostumarem a uma nova institucionalidade, que amplia a complexidade do ser e fazer docente e do docente gestor.

Outra mudança na autonomia institucional do IFNMG foi a forma de oferta de cursos. A Lei $n^{\circ}$ 11.892/2008 e o Decreto $n^{\circ} 5.840 / 2006$ passaram a delimitar os percentuais de oferta de vagas e tipos de cursos na instituição: 20\% das vagas voltadas para cursos de licenciatura e de formação pedagógica, como já referido, e 50\% para cursos técnicos, sendo que, desse percentual, 10\% deveriam ser destinados ao Programa Nacional de Integração da Educação Profissional com a Educação Básica na Modalidade de Educação de Jovens e Adultos (PROEJA).

Observou-se que o IFNMG tem tido dificuldades de alcançar as metas estabelecidas para a oferta do PROEJA e das licenciaturas. No caso do PROEJA, a dificuldade se pauta na dificuldade que os docentes têm para lecionar, sem a devida formação, para jovens e adultos, um público com especificidades e necessidades pedagógicas bem específicas. 0 mesmo motivo pode ser a causa do não atendimento ao percentual exigido pela lei para a oferta de licenciaturas, um tipo de curso historicamente marcado pela desvalorização da profissão, pelo baixo status social e pelo alto número de evasão, acrescidos da dificuldade que docentes bacharéis têm em formar licenciados, o que propicia resistências, tanto internas (docentes e gestores, por exemplo), quanto externas à instituição, já que a sociedade tende a solicitar e procurar cursos que julgam ter melhor status social. 
Ainda referente à autonomia da instituição, a Lei n 11.892/2008 voltou os objetivos e as finalidades do IFNMG aos interesses do setor produtivo, na medida em que exige do ensino, da pesquisa e da extensão vínculos com os APL. São perceptíveis as tentativas de aproximar os setores produtivos ao IFNMG, sujeitando a instituição ao mercado. Exige-se uma vinculação, quase que orgânica, das atividades desenvolvidas pelos docentes com os APL, pois esses arranjos são colocados como eixo balizador da tríade ensino, pesquisa e extensão. As pesquisas desenvolvidas devem ser aplicadas ao avanço, à inovação e ao desenvolvimento desses setores; as atividades de extensão devem estar voltadas à prestação de serviços técnicos; e o ensino, à formação de mão de obra, atendendo à demanda dos APL e favorecendo, assim, os interesses do mercado. Características diretamente relacionadas ao novo marco legal da inovação, conhecido como Código de Ciência, Tecnologia e Inovação (CTEt). ${ }^{8}$ Dessa forma, o vínculo dos APL com as atividades desenvolvidas pelos IF e a aprovação da referida lei demonstram as concepções governamentais oficiais de ciência para o desenvolvimento do país.

Apesar disso, durante o estudo, percebeu-se que há indefinições ou falta de clareza sobre os APL, por parte dos docentes no IFNMG. Alguns dos docentes entrevistados incorporam, de forma acrítica, o discurso dos documentos oficiais que tratam do vínculo dos IF com os APL. Outros não conhecem ou não percebem o vínculo da instituição com os APL. Nenhum dos docentes entrevistados percebe a lógica mercantil, que busca aproximar os setores produtivos à instituição, no discurso sobre os APL nos IF. Tal fato representa um risco diante da mercantilização da educação superior pública em curso no país, desde a década de 1990, que coloca a infraestrutura das IES e os servidores públicos a serviço de interesses privados.

Em geral, a ifetização é percebida pelos docentes entrevistados como um processo positivo, porque possibilitou o crescimento da instituição, ofereceu autonomia para criar cursos, aumentou o quadro de pessoal e possibilitou acesso a mais recursos para investir em infraestrutura, equipamentos e materiais. Os docentes avaliam, ainda, como positivas a interiorização e a democratização do acesso à educação superior pública na região Norte do Estado de Minas Gerais.

No entanto, muitos dos entrevistados afirmam que, apesar do aumento significativo do volume de investimentos recebidos, este foi insuficiente para atender ao processo de expansão estabelecido para a instituição. Afirmam também que o aumento no número de servidores da instituição não foi suficiente para atender a todas as demandas postas à consolidação dos IF. São recorrentes as reclamações com relação à falta de pessoal, principalmente de técnicos administrativos, para o apoio às atividades docentes. Essa insuficiência de quadros tem acarretado a assunção de algumas funções administrativas pelos docentes e contribuído para a precarização e a intensificação do trabalho destes.

0 aumento da oferta de educação superior é uma das mudanças mais significativas no âmbito da instituição. Há um evidente interesse dos docentes pela oferta desse nível de ensino, que, na percepção de alguns, possibilitaria a eles e à instituição uma posição de maior status e reconhecimento social. Outros motivos apontados pelos entrevistados para acolher bem essa

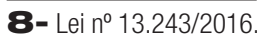


oferta se vinculam a melhores perspectivas na relação professor-estudante, por considerarem que esta pode ser favorecida pela maturidade dos discentes. A expansão de cursos foi identificada por alguns docentes logo nos três primeiros anos da transformação em IFNMG. Antes do processo de ifetização, eram ofertados seis cursos superiores, sendo cinco deles pelo antigo CEFET-Januária e um pela antiga EAF-Salinas. Em 2014, esse número aumentou três vezes e, em 2018, a projeção é de que seja cinco vezes maior do que o registrado em 2008.

No âmbito do IFNMG, verificou-se que problemas nas condições de trabalho dos docentes, expostos pela expansão da educação superior, interferem no exercício da docência nos cursos superiores. 0 aumento do número de cursos, vagas e matrículas chegou primeiro que a contratação de pessoal e a ampliação e implantação da infraestrutura necessária. Os processos licitatórios para contratação de serviços são morosos; faltam ou estão atrasadas as construções de laboratórios; há insuficiência de recursos materiais, de bibliotecas e até de salas de aulas. As regulamentações que orientam e gerenciam a oferta de educação superior, em âmbito institucional, também chegaram a passos lentos, o que sujeita a atuação docente a situações de incertezas e insegurança.

Na nova organização acadêmica e curricular do IFNMG, o professor passa a integrar uma área de conhecimento, podendo atuar em distintos cursos, disciplinas e atividades, ainda que, em alguns casos, sua formação seja insuficiente.

Observa-se que esses docentes são instados a inventar e reinventar espaços que estão ainda em construção, para diferentes atividades teóricas e práticas; lidar com relações diversas entre professores com concepções distintas sobre o fazer educação ou ser instituição; gerenciar relações com estudantes de diferentes faixas etárias, em tempos, níveis e objetivos diferentes. Muitos deles se apresentam como sedentos por adquirir conhecimentos e conferir qualidade ao ensino, ávidos para assumir as funções de gestor, pesquisador, inventor, inovador e extensionista, em prol de melhor posição na carreira, com as retribuições econômicas que tais inserções possam implicar, o que pode evidenciar a emersão da lógica produtivista e a meritocracia que fomentam a competição e o individualismo entre os docentes, bem como a autointensificação do trabalho, já presentes nas universidades públicas.

Embora as atividades de pesquisa e extensão sejam finalidades do IFNMG, entre os docentes há desentendimentos quanto à incorporação destas às suas atribuições. Isso pode ser explicado pelo fato de a instituição haver se dedicado, por muitos anos, aos cursos técnicos, que não exigiam pesquisa e nem extensão. Acrescenta-se a isso o fato de que o ensino, a pesquisa e a extensão não são percebidos, por todos os docentes, como um sistema articulado e indissociável. Além do mais, alguns dos docentes entrevistados afırmam não encontrar condições e espaços para desenvolver essas atividades, uma vez que precisam se submeter a editais e disputar, com os pares, os escassos recursos. Há a percepção de que não contam com recursos materiais e humanos suficientes e de que já há uma sobrecarga com a intensidade e a complexidade das atividades do ensino da EPT.

No que se refere às atividades que envolvem a administração no IFNMG, a maioria dos gestores entrevistados aponta que é uma atividade intensa que exige muitas horas de dedicação. Considera-se a experiência da gestão como enriquecedora, mas destaca-se a 
existência de dificuldades para conciliar os encargos administrativos com outras atribuições docentes, tais como pesquisa e publicações.

Percebe-se que, no IFNMG, a atividade de ensino aparece como a mais leve, enquanto a gestão, a pesquisa e a extensão são percebidas como penosas. Essa percepção sugere que a atividade de ensino, tradicional nas instituições da Rede Federal, continua a ser percebida como preferencial, ainda que as demais sejam exigidas. E o peso dessas outras atividades pode ser atribuído à falta de condições objetivas para sua realização.

Dois tipos de avaliação incidem sobre o trabalho docente no IFNMG: a avaliação da instituição, enquanto IES, para fins de regulação, avaliação e supervisão; e a avaliação de desempenho, para fins de progressão na carreira. Tais avaliações são apontadas como fatores de conflito, diante da perda de autonomia da instituição e do aumento de controle e aferição sobre alcance das metas externas, a fim de inseri-la no mercado educacional que as políticas atuais buscam conformar, como já referido. Ao passarem por esse tipo de avaliação, sofrem com seus efeitos taxativos. Tal sofrimento é ainda mais intensificado pelo fato de os IF serem avaliados por meio de instrumentos que não acolhem suas especificidades, a exemplo do que acontece nas avaliações para fins de recredenciamento, pelas quais são avaliadas como universidades sem o serem.

No que se refere à avaliação de desempenho para fins de progressão na carreira, observa-se que, com as novas classes do plano de carreira dos professores do MS e da EBTT (Lei no 12.772/2012), foram estabelecidos novos critérios para as promoções e progressões, e isso tem sido feito com prioridade ao caráter meritocrático. Esse novo plano propicia o aumento da concorrência, da competitividade entre os pares na organização do trabalho, do produtivismo, da meritocracia e do empreendedorismo, já que estes passam a nortear os critérios de promoção. Neste sentido, observa-se que a Lei n ${ }^{\circ}$ 12.772/2012 alterou a concepção de trabalho, tanto dos professores da EBTT, quanto do MS. As atividades de gestão institucional, pesquisa e extensão ganham relevância e isso pode vir a ser um empecilho à promoção e à progressão, pois não há espaços para todos ocuparem tais cargos/atribuições. A esse respeito, verificou-se, no IFNMG, que a ausência desses espaços coloca em risco também a indissociabilidade entre o ensino, a pesquisa e a extensão, necessária à educação superior.

Com efeito, a ifetização trouxe aos docentes do IFNMG mais trabalhos, em particular o trabalho do tipo polivalente, que fez com que eles tivessem de se desdobrar em diversas funções: trabalhar em diversos programas e projetos institucionais; participar de reuniões de naturezas diversas; desempenhar atividades típicas da secretaria acadêmica e do setor de compras; participar do planejamento da construção de novos laboratórios, entre outros. Expressões como "dificuldade", "coisa nova para mim" e "sobrecarga" foram recorrentes nas falas dos entrevistados. Além de lidarem com a novidade de trabalhar com a educação superior, trabalham, concomitantemente, com a educação básica, envolvem-se em programas institucionais e tentam cobrir as lacunas institucionais que a falta de recursos humanos, materiais e infraestruturais lhes impõe. Em outros termos, como retrata Dal Rosso (2008), o trabalho docente ganhou intensidade, pois exige do docente maior dispêndio (qualitativo ou quantitativo) de energias (físicas, psíquicas e emocionais). 
Assimilar essas alterações, no contexto do rápido e significativo processo de expansão de educação superior e de configuração dos IF, é uma tarefa difícil que, por um lado, tem modificado e intensificado o trabalho docente, tanto na condição de regente como de pesquisador e gestor. De outro lado, tem trazido, como novidade, o agrupamento de escolas e, por conseguinte, a redução drástica do número de gestores, que se constituem interlocutores diretos com o MEC. Todo esse conjunto de mudanças tão complexas exige discussões, reflexões e estudos aprofundados para que se possa compreender e analisar seus múltiplos efeitos.

\section{Considerações finais}

Este estudo reuniu evidências de que o trabalho docente exercido nos cursos superiores do IFNMG é de natureza complexa, mas possui muitas peculiaridades e também muitos pontos comuns com o trabalho de docentes situados em outros espaços, na atualidade. Essa complexidade, presumivelmente, apresenta-se nos demais IF, pois todos tiveram de obedecer às mesmas diretrizes para seu reordenamento. De todo modo, é importante estudar a realidade de outras instituições congêneres para identificar similitudes e discrepâncias.

A criação dos IF no Brasil é fruto de uma política pública que anunciou, como sua finalidade, ampliar as oportunidades de acesso à educação pública a partir de 2008. Contudo, na prática (e o IFNMG é exemplar), o processo que vem se desencadeando nessas instituições as tem transformado significativamente, tanto em suas finalidades como na forma de cumpri-las, e, paralelamente, tem submetido os docentes à intensificação e à precarização do trabalho.

Tal processo é repleto de pressões e tensões que afetam o cotidiano dinâmico das relações no interior da instituição, pela radicalidade das mudanças, pelas múltiplas contradições entre o prescrito e o real, e pelas incertezas ante a ifetização e o futuro dessas instituições, bem como o futuro dos próprios trabalhadores docentes.

Pôde-se inferir que a natureza complexa do trabalho docente no IFNMG - presente, de alguma maneira, em todos os níveis, etapas, modalidades e instituições de ensino - e a precarização que lhe acompanha inserem-se em um processo mais amplo de transformações na sociedade, desde o início da década de 1990, processo este que introduz, gradual e progressivamente, outra lógica - a gerencial - na atuação do Estado, em especial na área social e, em seu interior, na educação. Trata-se de uma lógica de empresariamento, que destitui direitos à educação pública e gratuita e, concomitantemente, derrui direitos do trabalho daqueles que exercem suas atividades nas instituições públicas correspondentes.

Com o ajuste estrutural anunciado e posto em prática em 2015 e intensificado pelo Governo Michel Temer (2016-atual), essa situação tende a ser agravada, haja vista as reformas em curso e as recentes legislações aprovadas e/ou em vias de aprovação. Chamam a atenção, nesse sentido: a) a Lei $n^{\circ} 13.135 / 2015$, que alterou as regras e reduziu direitos à pensão por morte; b) a Emenda Constitucional no 95/2016, chamada Lei do Teto de Gastos, que congelou os investimentos públicos em áreas sociais por 20 anos e limita, entre outras coisas, a realização de concursos para a educação federal; c) a Lei n ${ }^{\circ}$ 
13.429/2017, que admitiu a terceirização (atividade-fım e atividade-meio) das empresas, nas esferas pública e privada, o que implica aprofundar a precarização das relações de trabalho; d) a tramitação da reforma da previdência, ${ }^{9}$ que foi acelerada, sob alegação de um défıcit no seu orçamento, o que é desmentido por diversos especialistas. Tal proposta de reforma ameaça o direito à aposentadoria conquistada, após anos de lutas, e abre espaço para a especulação de capitais, nos fundos privados de pensão.

Esse conjunto de medidas, denominado por muitos como pacote de maldades, tem provocado insatisfação crescente entre os servidores públicos e demais trabalhadores de diversos setores, bem como entre aposentados, pensionistas e jovens estudantes.

Enquanto o governo, representando os capitais que serão beneficiados por tal pacote, avança na aprovação das medidas legais que dão substrato às reformas que afetarão profundamente a classe trabalhadora, no presente e no futuro - estrangulando as atividades universitárias, por meio de cortes de verbas e programas destinados à educação superior e expandindo o empresariamento da educação -, os docentes e demais trabalhadores buscam se organizar e lutar em defesa do direito à educação pública, gratuita e de qualidade e do estatuto docente a ela correspondente. Para tanto, nem sempre podem contar com suas organizações sindicais, muitas delas tomadas pela burocratização degradada.

De todo modo, o resultado dessa luta de classe explícita e inegável, que parece se expandir na atualidade, será dado na prática social, e suas consequências se farão visíveis.

\section{Referências}

AMARAL, Nelson Cardoso. Autonomia e financiamento das IFES: desafios e ações. Avaliação, Campinas, v. 13, n. 3, p. 647-680, nov. 2008.

BERNARD0, João. Democracia totalitária: teoria e prática da empresa soberana. São Paulo: Cortez, 2004.

BRASIL. Concepções e diretrizes da educação profissional e tecnológica: política da EPT 2003-2010. Brasilia, DF: MEC-SETEC, 2003.

BRASIL. Pátria educadora: a qualificação do ensino básico como obra de construção nacional. Brasília, DF: MEC, 2015. Versão preliminar.

BRASIL. Termo de acordo de metas e compromissos do Ministério da Educação/Institutos. Brasília, DF: MEC-SETEC, 2009.

BRASIL. Uma nova proposta de educação profissional tecnológica: concepções e diretrizes dos institutos federais. Brasília, DF: MEC-SETEC, 2010.

COSTA, Evelyn Hellen Sousa; BRAGA, Lucelma Silva; FERREIRA, Ruan Marcus de Jesus Pinheiro. 0 processo de expansão das universidades brasileiras e os impactos no trabalho docente: elementos para análise da

9- PEC nº 287/2016. 
Universidade Federal do Tocantins. In: SEMINÁRIO NACIONAL UNIVERSITAS/BR, 22., 2014, Natal. Anais... Natal: [s. n.], 2014. p. 105-120.

DAL ROSSO, Sadi. Mais trabalho! A intensificação do labor na sociedade contemporânea. São Paulo: Boitempo, 2008.

FREITAS, Luiz Carlos. Os reformadores empresariais da educação: da desmoralização do magistério à destruição do sistema público de educação. Educação \& Sociedade, Campinas, v. 33, n. 119, p. 379-404, abr./jun. 2012.

GOMES, Alfredo Macebo; MORAES, Karine Numes de. Educação superior no Brasil contemporâneo: transição para um sistema de massa. Educação \& Sociedade, Campinas. v. 33, n. 118, p. 171-190, jan./ mar. 2012.

GRISCHKE, Paulo Eduardo. 0 paradigma da colaboração nas políticas públicas para a educação profissional e suas implicações sobre o trabalho docente. 2013. Tese (Doutorado em Educação) - Universidade Federal de Pelotas, Pelotas, RS, 2013.

LIMA FILHO, Domingos Leite. A reforma da educação profissional no Brasil dos anos noventa. 2002. Tese (Doutorado em Educação) - Universidade Federal de Santa Catariana, Florianópolis, 2002.

MACHADO, Lucília Regina de Souza. Diferenciais inovadores na formação de professores para a educação profissional. Revista Brasileira da Educação Profissional e Tecnológica, Brasília, DF, v. 1, n. 1, p. 8-22, jun. 2008.

MAUÉS, Olgaíses Cabral. Educação superior e o trabalho docente no contexto da crise do capital. In: CONGRESSO IBERO-LUSO-BRASILEIROS DE POLÍTICA E ADMINISTRAÇÃO DA EDUCAÇÃO, 6., 2010, Lisboa. Anais... Lisboa: Anpae, 2010. Disponível em: <http://www.anpae.org.br/iberolusobrasileiro2010/ cdrom/95.pdf>. Acesso em: 14 mar. 2015. p. 1-13.

MELO, Savana Diniz Gomes. Trabalho docente na educação profissional. In: OLIVEIRA, Dalila Andrade; DUARTE, Adriana Maria C.; VIEIRA, Lívia Maria F. (Org.). Dicionário de trabalho, profissão e condição docente. Belo Horizonte: UFMG/Faculdade de Educação, 2010. Disponível em: <http://www.gestrado.net. br/pdf/428.pdf>. Acesso em: 12 mar. 2015. p. 1-7.

NEVES, Clarissa Eckert Baeta. Ensino superior no Brasil: expansão, diversificação e inclusão. Grupo de Estudos sobre Universidade (GEU). Porto Alegre: UFRGS, 2012.

OLIVEIRA, Dalila Andrade; ASSUNÇÃO, Ada Ávila. Condições de trabalho docente (Verbete). In: OLIVEIRA, Dalila Andrade; DUARTE, Adriana Maria C.; VIEIRA, Lívia Maria F. (Org.). Dicionário de trabalho, profissão e condição docente. Belo Horizonte: UFMG/FAE, 2010. Disponível em: <http://www.gestrado.net. $\mathrm{br} / \mathrm{pg}=$ dicionario-verbetes\&id=390 $>$. Acesso em: 14 fev. 2015. p. 1-4.

OTRANTO, Célia Regina. A reforma da educação profissional e seus reflexos na educação superior. Revista Temas em Educação, João Pessoa, v. 22, n. 2, p. 122-135, jul./dez. 2013. 
PAULA, Alisson Slider do Nascimento. 0 Programa REUNI em foco: intensificação e precarização do trabalho docente. Revista Espaço Acadêmico, Maringá, n. 170, jul. 2015.

SERAFIM, Milena Paivan. 0 processo de mercantilização das instituições de educação superior: um panorama do debate nos EUA, na Europa e na América Latina. Avaliação, Campinas, v. 16, n. 2, p. 241265, jul. 2011.

SILVA JR., João dos Reis; SGUISSARDI, Valdemar. Educação superior: análise e perspectivas de pesquisa. São Paulo: Xamã, 2001.

SILVA, Paula Francisca da. A expansão da educação superior e o trabalho docente no Instituto Federal do Norte de Minas Gerais. 2015. Dissertação (Mestrado) - Faculdade de Educação da Universidade Federal de Minas Gerais, Belo Horizonte, 2015.

Submetido em: 14.03.2017

Aprovado em: 07.06.2017

Paula Francisca da Silva é graduada em Pedagogia, especialista em Educação a Distância e Docência do Ensino Superior, mestre em Educação. Atualmente é pedagoga no Instituto Federal do Norte de Minas Gerais (IFNMG), em Montes Claros (MG), doutoranda em Educação e integra 0 Grupo de Pesquisa sobre a Universidade (Universitátis), da Faculdade de Educação da Universidade Federal de Minas Gerais (FaE/UFMG).

Savana Diniz Gomes Melo é graduada em Serviço Social, mestre e doutora em Educação, pós-doutora com vínculo na Faculdade de Ciências da Educação da Universidade de La Coruña (Galícia, Espanha). Atualmente é professora adjunta, vice-coordenadora da linha de pesquisa Políticas Públicas e Educação do Programa de Pós-graduação em Educação da Faculdade de Educação da Universidade Federal de Minas Gerais (FAE/UFMG) e coordenadora do Grupo de Pesquisa sobre a Universidade (Universitátis/FaE/UFMG). 